\title{
Coronaviruses: The Most Dangerous Pathogen of Present Era
}

\author{
Rajendran R', $\underline{\text { Sheela Devi D }}{ }^{2}, \underline{\text { nnusree SB }}^{3}, \underline{\text { Regu }}^{4}, \underline{\text { Sharma SN }}^{5}$ \\ ${ }^{1,}$ Deputy Director, ${ }^{3}$ Research Assistant, ${ }^{4}$ Additional Director, National Centre for Disease Control, Government of India, Calicut, \\ Kerala, India. \\ ${ }^{2}$ Former Head, Department of Zoology, MM NSS College, Kottayam, Kollam, Kerala, India. \\ ${ }^{5}$ Consultant, National Centre for Disease Control, Ministry of Health and Family welfare, Government of India, 22 Sham Nath \\ Marg, Delhi, India.
}

DOI: https://doi.org/10.24321/0019.5138.202036

\section{I $\quad \mathbf{N} \quad \mathbf{F} \quad \mathbf{O}$}

\section{Corresponding Author:}

Rajendran R, National Centre for Disease Control,

Government of India, Calicut, Kerala, India.

E-mail Id:

rajendran061@gmail.com

Orcid Id:

https://orcid.org/0000-0003-2080-9723

How to cite this article:

Rajendran R, Sheela Devi D, Anusree SB, Regu K, Sharma SN. Coronaviruses: The Most Dangerous Pathog, en of Present Era. J Commun Dis 2020; 52(4): 17-28.

Date of Submission: 2020-11-10

Date of Acceptance: 2020-12-10

\section{$\begin{array}{llllllll}\mathbf{A} & \mathbf{B} & \mathbf{S} & \mathbf{T} & \mathbf{R} & \mathbf{A} & \mathbf{C} & \mathbf{T}\end{array}$}

Coronaviruses are the major group of viruses belonging to the Order Nidovirales. Four families- Coronoviridae, Arteriviridae, Mesoniviridae, and Roviviridae are included in this Order. All CoVs are pleomorphic RNA viruses characterized by club-like spikes that project from their surface. These viruses have unusually large RNA genome, with a unique replication strategy. CoVs were not considered as highly pathogenic for humans until the emergence of SARS-CoV in 2002-03 in China. The emergence of another highly pathogenic CoV, Middle East Respiratory syndrome (MERS-CoV) in the Middle East Countries confirmed the occurrence of highly pathogenic human viruses among the Coronaviruses. In this article we provide a brief introduction to coronaviruses, mode of action, pathogenesis, current situation, prevention and control of COVID-19.

Keywords: CoV, SARS, COVID-19, Genome Variation

\section{Introduction}

Coronaviruses (CoV) are a large family of Ribonucleic Acid (RNA) viruses that cause diseases in mammals, including humans and birds. In humans, the virus causes illnesses which range from common cold to more severe respiratory infections. In cows and pigs CoV may cause diarrhea, but in chicken the virus can cause upper respiratory infections. There are no vaccine or antiviral drugs for the prevention or treatment of this zoonotic viral disease.

The name "coronavirus" is originated from the Latin corona and the Greek korone meaning crown or halo. These viruses are characterized by club-like spikes that projected from their surface and it looks like a crown and hence the name coronavirus. CoV are enveloped, single-stranded, positive sense RNA viruses with a comparatively large genome size of 26 to $32 \mathrm{~kb}$, classified under the family Coronaviridae in the order Nidovirales. ${ }^{1}$ Many of the human CoVs are either zoonotic or circulate in animals. $\mathrm{CoV}$ can be classified in to four genera, including $\alpha-\mathrm{CoV}, \beta-\operatorname{CoV}, \gamma-\operatorname{CoV}$ and $\delta-\mathrm{CoV}^{2}$ $\alpha$ - and $\beta$-CoV usually infect mammals, whereas $\psi$ - and $\delta$-CoV can infect birds.

Corona viruses may cause significant percentage of common colds in human beings. Some common symptoms of infection by CoVs include respiratory illness, fever, cough, and breathing difficulties. In acute cases, infection may lead to pneumonia, Severe Acute Respiratory Syndrome (SARS), failure of kidney and may leads to death. Seven strains of human coronaviruses are identified so far. (1) Human coronavirus 229E (HCoV-229E), (2) Human coronavirus 
OC43 (HCoV-OC43), (3) Severe Acute Respiratory syndrome coronavirus (SARS- CoV), (4) Human coronavirus NL63 (HCoV-NL63), (5) Human coronavirus HKU1, (6) Middle East Respiratory Syndrome coronavirus (MERS-CoV), (7) Novel coronavirus (2019-nCoV) or COVID-19. The coronaviruses such as HCoV-229E, -NL63,-OC43, and -HKU1 unceasingly spread in the human population and cause respiratory illnesses in adults and children globally. ${ }^{3}$ Swine Acute Diarrhea Syndrome Coronavirus (SADS-CoV), a HKU2-related bat $\mathrm{CoV}$, can cause diarrhea in pigs.

In addition to numerous nonstructural proteins inclusive of the RNA- dependent RNA polymerase (RdRp), the viral RNA encodes the structural proteins such as the Nucleocapsid (N) protein encircling the RNA genome and three membrane proteins; the S-glycoprotein, the Matrix (M) protein, and the Envelop (E) protein (Figure 1). ${ }^{1}$ The S-glycoprotein on the surface of coronavirus (CoV) can attach angiotensin converting enzyme- 2 (ACE2), the cellular receptor, on the surface of human cells. ACE2, is responsible for the cross species and human-to-human transmission, is found in the lower respiratory tract of humans. ${ }^{4}$

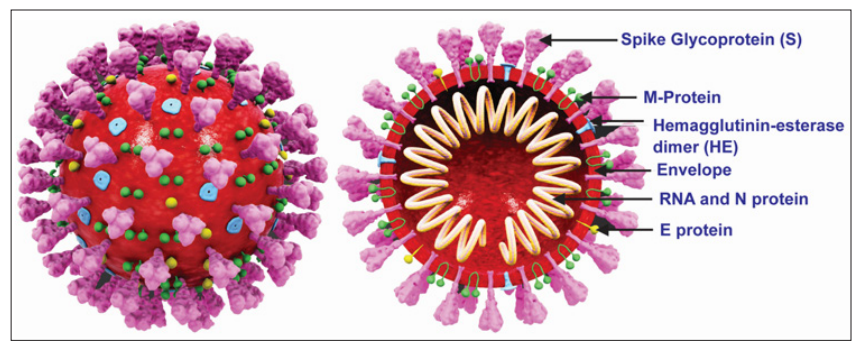

Figure I.Structure of Coronavirus

\section{Coronaviruses - a Brief History}

In 1937, the first coronavirus, the Infectious Bronchitis Virus (IBV), was isolated from chicken embryos. ${ }^{5}$ Following this detection, a number of coronaviruses have been isolated from wild as well as farm animals and pets. The pathogenic viruses belong to the genera mammalian- associated $\alpha$ and $\beta-\mathrm{CoV}$ and bird - related $\gamma$ - and $\delta$-CoV. Coronaviruses primarily animal associated pathogens such as Avian Infectious Bronchitis Virus (AIBV), Mouse Hepatitis Virus (MHV) and the Transmissible Gastroenteritis Virus (TGV) of swine. CoVs are known to cause diarrhea in calves, piglets and dogs. The significance of coronaviruses seen in human feces is not yet established fully. ${ }^{6}$

It is to be noted that there are many coronavirus infections in animals which are of asymptomatic in nature. However Transmissible Gastroenteritis Coronavirus (TGEV) can cause diarrhea in pigs. The extent of coronavirus diseases in animals vary from mild to severe, respiratory, intestinal, or systemic illnesses. ${ }^{7}$ Coronaviruses are fast mutating in nature and due to their error prone RNA-dependent RNA- polymerase, the duplication of genetic information occurs. Moreover, homologous recombination frequently occurs in coronaviruses. ${ }^{8}$ These characteristics enable the coronaviruses to infect numerous species.

Following the SARS pandemic in 2002-03, many investigators started studies on wild animals mainly to look into how the different types of animals are accommodating the viruses, often without having any harm to them. The greatest multifarious of coronavirus has so far been detected in bats. Bats have been recognized as the natural reservoirs of a number of pathogenic viruses notably Nipah and Ebola virus. ${ }^{9}$ India has a rich and diverse population of bats with about 117 bat species have been recorded so far. Nipah virus in Pteropus medius (family-Pteropodidae), Malsoor virus, Timan virus and a novel Adenovirus in Rousettus leschenaultia are excellent examples for batvirus association. In 2018 and 2019 Nipah outbreak in Kerala, the possible role of bats could be established with the detection of coronavirus positivity in Pteropus and Rousettus bats collected from the disease affected areas of Kerala. ${ }^{10,11}$ Potentially pathogenic CoVs detection in Indian bats emphasizes the need for elaborate screening for new viruses in them. Though the role of Himalayan palm civet as an intermediate animal for the spread of SARS-CoV to humans and similarly, camel for the Middle East Respiratory Syndrome (MERS-CoV) is documented, some gaps exist in establishing the part of wild animals and zoonotic CoVs in disease transmission to human population.

\section{Coronaviruses in Humans}

\section{Less Pathogenic Human Coronaviruses}

In 1960s, the test results of the samples taken from the nasal cavities of human patients with common cold were positive for two viruses. These two viruses were the first human coronaviruses and subsequently designated as HCoV-229E and HCoV-OC43. ${ }^{12,13}$ HCoV-229E (family - Coronaviridae) can infect both humans and bats. The transmission is usually via droplet-respiration and fomites. The symptoms usually limited to common cold, but occasionally lead to pneumonia and bronchitis. Human coronavirus OC43 (family-Coronaviridae) is a member of the Genus Betacoronavirus which infects human and cattle. Like HCoV-229E, this virus also causes common cold. Both these viruses can cause severe lower respiratory tract infections, including pneumonia in infants and elderly. At present, globally there are four human coronaviruses that circulate in human population. They are HCoV-229E, HCoV - OC43, HCoV - NL63, and HCoV-HKU1. Usually these 4 coronaviruses lead to only 'flu' likes symptoms or "common colds" in humans.

Human coronavirus NL63 (HCoV-NL63) was detected from a seven-month-old child who is suffering with bronchitis in 2004 from the Netherlands. Like other human coronaviruses, 
this virus also enveloped, positive sense, single stranded RNA virus. This virus is found mostly in young children as well as elderly with severe respiratory diseases. The virus is considered to be evolved from infected palm civets and bats. The transmission of the virus is through direct person-to-person. Outside the body, the virus can live for a week in wet media/ conditions and three hours on dry surfaces. Spread of -NL63 is through droplet ejection from the respiratory tract or through close contact.

Human coronavirus HKU1 is believed to be originated from infected mice. This virus was first identified in a 71 years old man who was under treatment for respiratory illness and pneumonia. HCoV-HKU1 is very much related to Mouse Hepatitis Virus (MHV) which is quite distinct from HCoV-OC43.

\section{Highly Pathogenic Human Coronaviruses}

\section{Severe Acute Respiratory Syndrome (SARS)}

In November 2002, an unusual pneumonia-like illness with high rate of nosocomial transmission was reported among health care workers of Guangdong province, in China. In the beginning of 2003, this infectious disease spread to Canada, Singapore, and Vietnam by travelers through Hong Kong. The samples of the patients who are suffering from pneumonia-like illness have been tested positive for SARSCoV. Genetic studies showed that the SARS-CoV isolates from Guangzhou area of Guangdong province is very similar to SARS-CoV spreading in other parts of the world.

SARS is a transmissible and sometimes fatal respiratory illness caused by a SARS Coronavirus (SARS-CoV), which belongs to the family of enveloped coronaviruses. SARS$\mathrm{CoV}$ has the same structural protein as earlier known groups of coronaviruses- HCoV-229E,-OC43, and -NL63. As shown in Figure 2, the structure of SARS-CoV has a spike glycoprotein(S), a membrane protein (M), Enveloped protein $(E)$ and Nucleocapsid protein $(N)$.

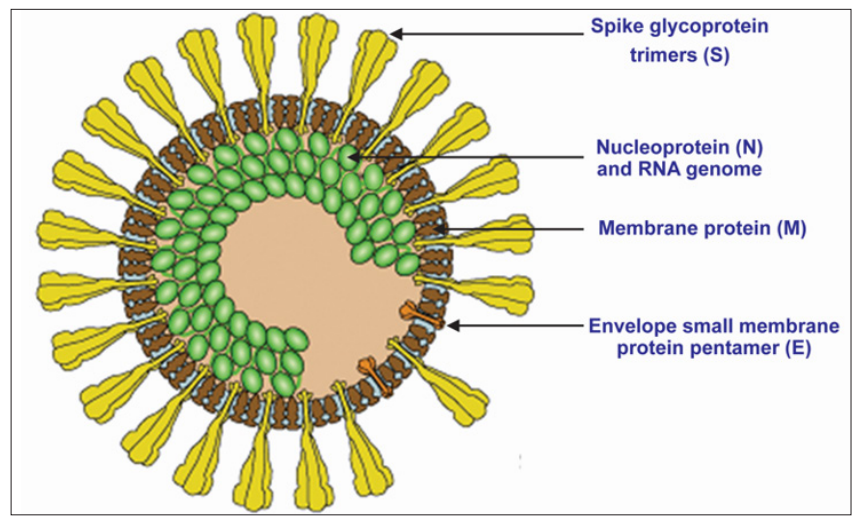

Figure 2.Structure of SARS - Coronavirus (SARS - CoV)

In 2003, a close variant of SARS-CoV has been detected from palm civets in Dongmen market Shenzhen. This led to the assumption that the palm civets might be responsible for the transmission of coronavirus to humans. In 2005, CoVs very similar to SARs-CoV were isolated from horseshoe bats. This made the investigators to suggest that bats may be the natural reservoirs of SARS-CoV.

The virus caused serious human respiratory diseases in China between November 2002 and July 2003. The outbreak has started in Guangdong Province, China in 27 November 2002. Initially it was thought a "flu outbreak". The disease claimed 8,096 cases with 774 deaths (Case fatality rate $9.6 \%)$ reported in 29 territories. ${ }^{14}$ The signs and symptoms include fever, muscle pain, cough, sore throat, etc. The most common symptom is fever above $38^{\circ} \mathrm{C}$ and in some cases it may lead to shortness of breath and pneumonia. Watery diarrhea may occur in the initial phase of the illness. The main route of spread of SARS-CoV is through contact of mucous membranes with respiratory droplets.

There are no antiviral drugs or vaccine for the treatment of SARS. Social distancing and home/hospital quarantine is the most effective methods to prevent the rapid spread of the disease. The most important preventive methods include Distancing, Hand washing and sanitizing practices (DHS). SARS being a viral disease, antibiotics are ineffective. Treatment is mainly supportive/ symptomatic, supplemental oxygen and mechanical ventilation, if required.

The SARS epidemic became a great public health concern in February 2003, when an American businessman developed pneumonia-like symptoms during his flight travel from China to Singapore. The flight stopped in Hanoi, Vietnam, where Johnny Chen, the victim died in Hanoi French Hospital. Carlo Urbani, the Italian doctor who was in the medical team, soon realized the risk of the illness and soon intimated to World Health Organization (WHO) and Vietnam Government. But unfortunately, the doctor succumbed to the disease in March 2003. The gravity of the symptoms of the disease awakened the global health authorities and compelled WHO to issue a global alert on 12 ${ }^{\text {th }}$ March 2003. Development of rapid test facilities and elaborate isolation arrangements controlled the rapid spread of SARS-CoV to a great extent. Many investigators initiated studies to find out the source of infection or the origin of the disease germ in China. Subsequently, SARS CoV could be isolated from Palm civets (Paguma sp.), raccoon dogs (Nyctereuteus sp.), ferret badgers (Melogale spp.), domestic cats and Chinese bats. ${ }^{15,16}$ Hence it was assumed that the virus might have spread from animals such as civet cats or bats to humans and subsequently human- to- human transmission was made possible. As per the reports and records available so far, no human infections with original SARS virus have been reported so far since 2004 . 


\section{Middle East Respiratory Syndrome (MERS)}

Middle East Respiratory Syndrome originated on the Arabian Peninsula which is caused by MERS-CoV. The structure of this virus is very similar to SARS-CoV and consisting of a Spike glycoprotein (S), a membrane protein (M), Enveloped protein (E) and nucleocapsid protein (E) (Figure 3).

About 10 years after the SARS-CoV outbreak in China, another virus highly deleterious to humans emerged in Saudi Arabia in 2012. The virus was isolated from a patient with severe pneumonia in Saudi Arabia in June 2012. Initially the virus was called Novel Coronavirus 2012, and later named as Middle East Respiratory Syndrome Coronavirus (MERS- CoV). ${ }^{17}$ Human to human transmission of MERS$\mathrm{CoV}$ was first confirmed in France and later in Tunisia. The MERS-CoV cases and deaths reported in Saudi Arabia as on $30^{\text {th }}$ October 2013 were 124 and 52 respectively.

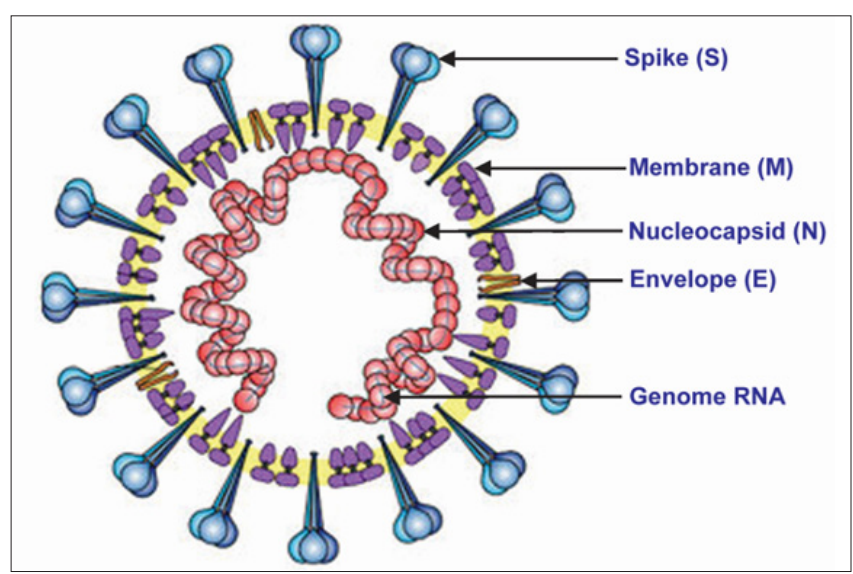

Figure 3.Structure of MERS - Coronavirus (MERS - CoV)

An outbreak of MERS-CoV reported in the Republic of Korea in May 2015 and this was probably the largest disease outbreak outside of the Middle East. Of the 2,468 MERS-CoV confirmed cases reported there, 851 people lost their life. The case fatality rate was approximately $34.5 \%$. MERS-CoV infection was mainly through human-to-human transmission.

The clinical features of MERS-CoV range from asymptomatic, mild symptoms to very severe pneumonia with acute respiratory distress syndrome. Sometimes it may lead to septic shock, multi organ failure and often resulting in death. The clinical presentation may be mild in those patients who do not have any major health issues. But in patients who are under treatment for illness of heart, lungs, kidney, etc. the MERS-CoV infection may be severe and sometimes fatal.

The natural reservoir of MERS-CoV is still uncertain, but bats may be one possible reservoir for this virus. It has been suggested that dromedary camels may be an important natural host for the maintenance and spread of this virus. It appears to be the major source of zoonotic human infection.

\section{Coronavirus Disease-20I9 (COVID-19)}

The 2019-20 coronavirus outbreak is an ongoing public health exigency of global concern. In late December 2019, a cluster of pneumonia of unknown origin was reported in Wuhan, Hubei province of China. Most of the earlier cases were attributed to Huanan Seafood Wholesale Market and hence the virus was thought to have an animal origin. The first sufferer of coronavirus infection was a 57 years old female, Wei Guixian, a shrimp vendor at the Huanan market in Hubei province. ${ }^{18}$ She developed 'flu' like symptoms including cold on 10th December, 2019 and consulted a nearby local hospital where Wei was given an injection. Next day, she felt more tiredness and forced to visit 'Eleventh hospital' in Wuhan. As cold and tiredness persisted, Wei has found no other way than to visit 'Wuhan Union Hospital' (WUH) one of the highest hospitals in Wuhan. She went to the hospital on $16^{\text {th }}$ December 2019.

Meanwhile, it has been learnt that many people rushing to WUH with 'flu' - like symptoms. As many people started coming to WUH with similar symptoms, the doctors suspected the illness may be due to some unknown germ, possibly virus infection related to Hunan seafood market. Wei Guixian's illness totally cured and regained the health. Wei was considered 'coronavirus patient zero' and believed that she got infection from a toilet she shared with meat sellers in the Hunan market. Several vendors selling fish/ meat products close to her also contracted the disease. This ascertained the connection of Hunan market in the spread of this contagious disease. Further, the Municipal Health Commission (MHC) confirmed that Wei was one among the 27 patients to test positive for the virus. In addition to this, she was one of 24 cases directly related to the Hunan market. This again strengthened the belief of the people about the Market's role on the emergence and spread of this highly contagious disease.

Meanwhile, the South Morning China Post dated $17^{\text {th }}$ November 2019, reported a 55 years old. Individual from Hubei province in China was the first person to have contracted this viral disease. The earliest reported symptoms occurred in Wuhan on $1^{\text {st }}$ December 2019, in a person who did not have exposure to the seafood market. All these reports indicate that in the initial stage, Wuhan health authorities were not serious in investigating and controlling the disease. Absence of a proper disease surveillance system in the beginning stage made inconclusive reports/opinions about the origin of the disease in Wuhan. This persuaded the researchers to track the origin of the virus other than the seafood market. Li Wenliang, an ophthalmologist of Wuhan Central Hospital, informed his former medical school classmates about the possibility of a dangerous 
virus behind the ongoing disease outbreak in a WeChat group after examining a patient's medical report with symptoms of the disease. He was warned by the Wuhan police on 3rd January 2020 for "making untrue comments". Unfortunately this prudent medical officer died on February 2020 after contracting the disease from a patient. Wuhan Government obliged Dr. Li Wenliang an apology after his death as a mark of realization of his foresightedness and great service to mankind.

In the midst of the controversies on the origin of the virus epidemic in China, the scientists from CDC, China tested about 600 samples including meat/ parts of wild animals and samples from the surroundings of Hunan market. About $5.6 \%$ of the samples tested showed that the virus originated from wild animals. The laboratory tests conducted using the body fluids and throat swab samples collected from the patients infected with flu-like symptoms showed that virus-specific nucleic acid sequences which is quite different from that of known and existing human coronaviruses. It is interesting to note that the SARS-CoV-2 detected from the patients is similar to some of the beta coronaviruses identified in bats. ${ }^{19}$

\section{Reservoirs and Hosts of Coronaviruses}

The origin and nature of transmission of pathogen are very important to formulate and implement the preventive measures to contain the infection. The scientists initially concentrated on palm civets and raccoon dogs as main reservoir of infection of SARS-CoV. The positive viral RNA could be detected only in samples isolated from the civets at the Hunan food market. This indicates there may be a primary host and civets may act as secondary hosts of this new viral infection. The molecular assessment study using the samples isolated from healthy individuals of Hong Kong in 2001 showed the presence of antibodies against SARScoronavirus. These are some of the evidences to indicate that SARS-CoV might have entered and circulated among human population before the 2003 SARS outbreak in China. The researchers later found the anti-SARS-CoV antibodies in Rhinolopus bats and hence they thought the bats might be acting as a source of viral replication. ${ }^{20}$

The Middle East Respiratory Syndrome coronavirus (MERS-CoV) also belongs to $\beta$-coronavirus and camels act as zoonotic source. MERS-CoV also detected in bats belonging to Pipistrellus and Perimyotis. This led to the conclusion that bats play an important role in spreading the virus. In a preliminary investigation, the researchers thought snakes can be a possible host of the virus. But the genome sequencing study revealed that the novel coronavirus is having much similarity with SARS-like bat viruses. Then the scientists thought that bats could be a key reservoir (Figure 4). Bats are potential reservoirs of human pathogenic viruses. They are known shelters of a wide range of coronaviruses. It is also well known that different types of bat populations are reported to have habitats in Western Ghats region, particularly in Kerala. Hence proactive surveillance of zoonotic infections in bats is the need of the present time.

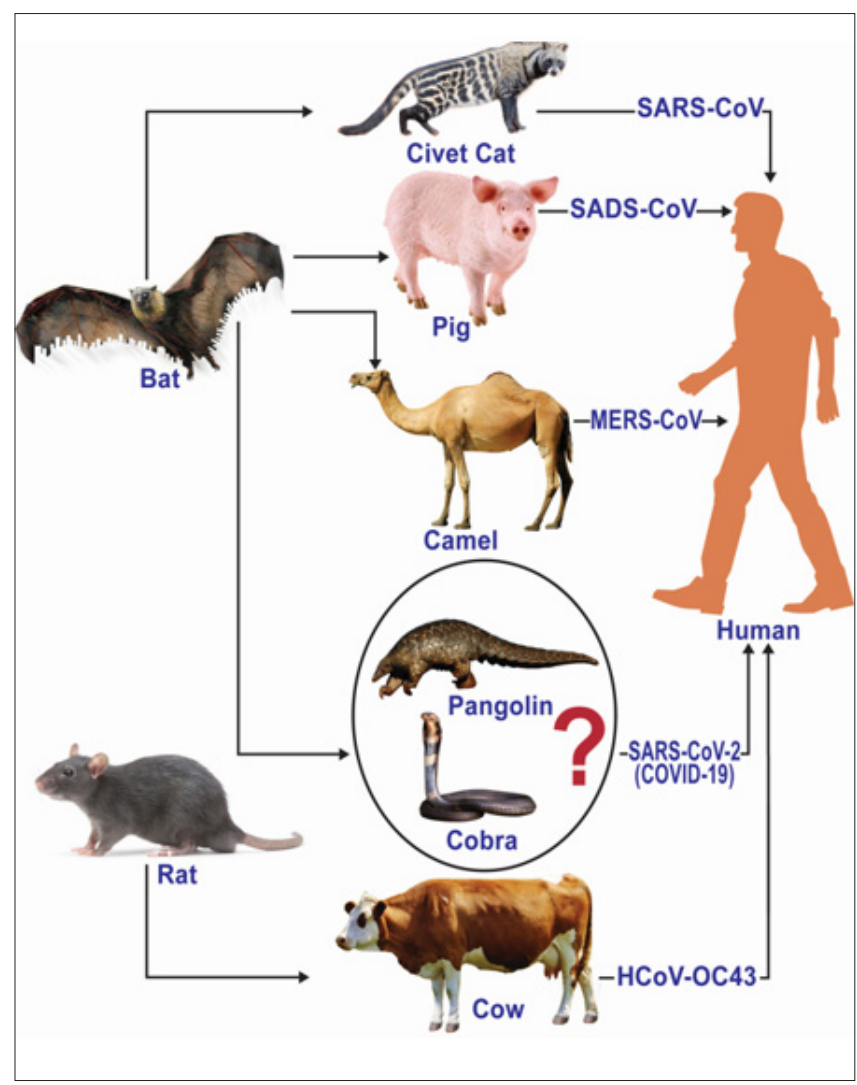

Figure 4.Coronavirus transmission from animal to human

\section{Entry Mechanism of Human Coronaviruses}

All human coronaviruses have specific genes in ORF1 regions that help proteins for viral replication and spike formation. The glycoprotein spikes are present on the outer surface of the coronaviruses. These spikes are capable for the attachment and entry of the virus to host cells (Figure 5). The virus may infect multiple hosts. This is possible because of the Receptor Binding Domain (RBD) is loosely attached among the virus. SARS-CoV and MERS$\mathrm{CoV}$ recognize exopeptidases as a main receptor for the entry to human cells. Other coronaviruses mostly recognize amino peptidases or carbohydrates as key receptors. ${ }^{21}$ The cellular proteases such as human airway trypsin- like protease (HAT), cathepsins and transfer membrane protease serine 2 (TMPRSS2) may favor the entry mechanism of a coronavirus. These cellular proteases split the spike protein and establish further penetration changes. The AngiotensinConverting Enzyme (ACE2) acting as a key receptor for SARS-coronavirus whereas dipepyidyl peptidase 4 (DPP4) is the main receptor for MERS-CoV. 
Table I.Comparative analysis of prominent biological traits of SARS-CoV, MERS-

CoV and SARS-CoV-2 (COVID-I9)

\begin{tabular}{|c|c|c|c|}
\hline Prominent traits & SARS-CoV & MERS-CoV & SARS-CoV-2 \\
\hline Emergence date & November-2002 & September-2012 & December-2019 \\
\hline Area of Emergence & Guangdong, China & Saudi Arabia & Wuhan, China \\
\hline $\begin{array}{c}\text { Current status of the } \\
\text { disease }\end{array}$ & $\begin{array}{c}\text { Fully controlled July } \\
2003\end{array}$ & $\begin{array}{c}\text { Last outbreak occurred in } \\
\text { Seoul, Republic of Korea in } \\
\text { December-2019 }\end{array}$ & Not controlled yet \\
\hline Key hosts & $\begin{array}{c}\text { Bat, palm civets and } \\
\text { Racoon dogs }\end{array}$ & Camels & Bat? \\
\hline No. of countries infected & 29 & 06 & More than 200 \\
\hline Entry receptor in humans & ACE2 & DPP-4 & ACE2 \\
\hline Sign and symptoms & $\begin{array}{c}\text { Fever, malaise, myalgia, } \\
\text { headache, diarrhea, } \\
\text { shivering }\end{array}$ & $\begin{array}{c}\text { Fever, cough, shortness of } \\
\text { breath, difficulty in breathing }\end{array}$ & $\begin{array}{c}\text { Fever, cough, shortness of } \\
\text { breath }\end{array}$ \\
\hline Disease caused & SARS, ARDS & MERS & SARS, COVID-19 \\
\hline Total infected persons & 8096 & 2468 (as of December 2019) & $\begin{array}{c}67,99173 \text { (as of 07, June } \\
2020)\end{array}$ \\
\hline Total recovered & 7322 & 1617 & $6,402,325$ \\
\hline Recovery rate & $90.44 \%$ & $65.52 \%$ & $94.16 \%$ \\
\hline Number of patients died & 774 & 851 & 397388 \\
\hline Case fatality rate & $9.56 \%$ & $34.48 \%$ & $5.84 \%$ \\
\hline
\end{tabular}

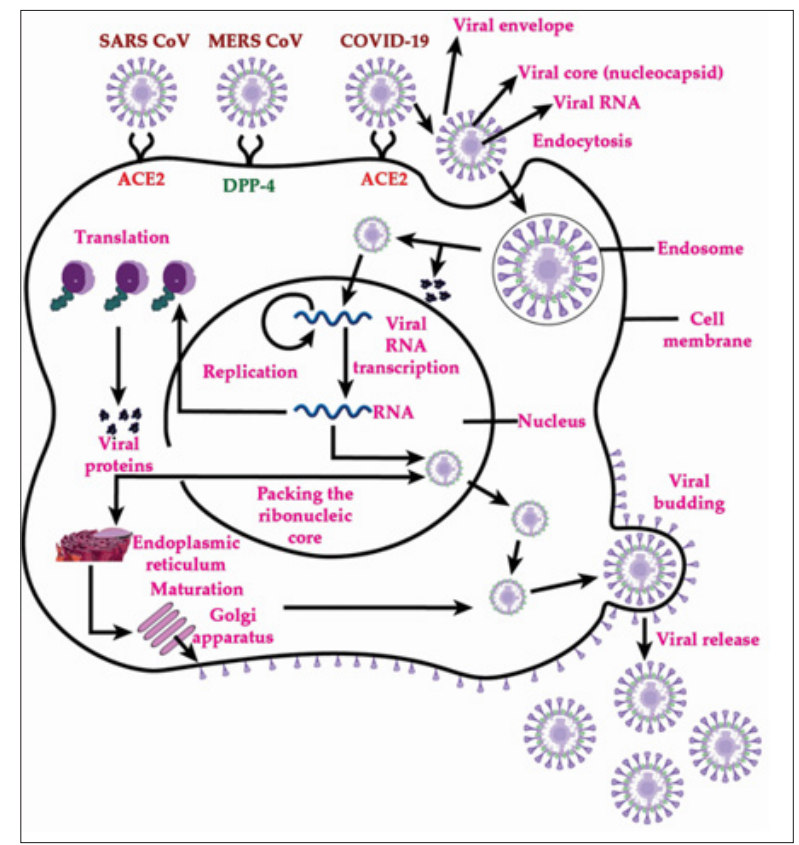

Figure 5.Mode of action of SARS-CoV, MERS-CoV and COVID-19

\section{SARS-CoV-2: Genomic Variations}

Ever since the establishment of a novel coronavirus in the spread of a highly infectious disease from Wuhan to world over, several scientists attempted to track down the etiology of the disease. One of the pertinent issues they wanted to solve was about the origin of the recent infection. Many assumptions/ hypothesis came from different sources. Some of the molecular scientists thought that genome sequencing may give a satisfactory answer to the existing issue. It has been found that the genome of novel coronavirus (SARS-CoV-2) has more than $80 \%$ identical with the human coronavirus (SARS- like bat CoV). The evolutionary scientists opined that SARS-CoV-2 remain close to group of SARScoronaviruses. The main difference between SARS-CoV and SARS-CoV-2 is in the absence of 8a protein. The fluctuation in the number of amino acids in $8 \mathrm{~b}$ and $3 \mathrm{c}$ protein in SARSCoV-2 is also a unique feature. It is worthwhile to note that the spike glycoprotein of SARS-CoV-2 is an association of bat CoV and an unknown beta-coronavirus. ${ }^{22}$ Both SARSCoV and SARS CoV-2 are using ACE2 for the entry and establishment of these disease germs to host cells. The mutation occurred in the spike protein of SARS-CoV is responsible for intensifying the binding affinity for ACE2.

\section{Diagnostic Testing}

There are mainly two methods for COVID-19 diagnostic testing. Real- Time reverse transcriptase PCR (rRT-PCR) and whole genome sequencing. Genome sequencing was used to facilitate early identification of the virus, most often this is used early in the disease outbreak. Currently, most of 
the COVID-19 tests are being done using rRT-PCR. The test can be done on respiratory samples such as throat swab or body fluids such as blood. Results are generally made available from hours to days.

The physicians are using another method of diagnosis which is based on clinical presentation such as visual signature patterns of COVID-19 in CT scans of the lungs.

Those who travelled to an area with ongoing community transmission of COVID-19 within the previous 14 days or had close contact with an infected person are considered to be high risk of having the disease.

\section{Symptoms of Coronaviruses}

Some common signs and symptoms of CoVs include fever, respiratory illness, cough, shortness of breath and other breathing difficulties. In some severe cases, infection may lead to pneumonia, severe acute respiratory syndrome, renal failure and sometimes even death (Figure 6).

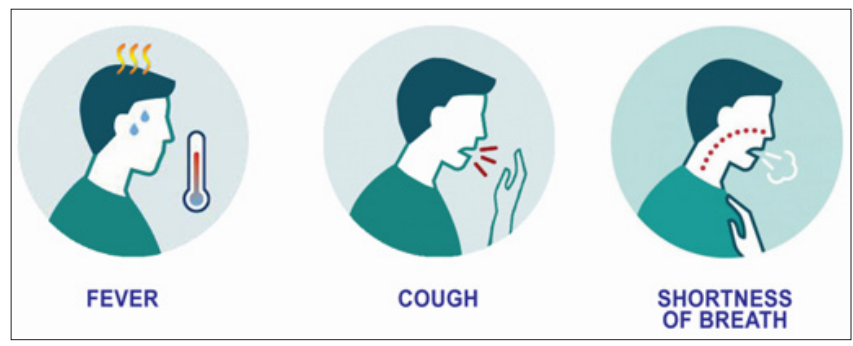

Figure 6.Symptoms of COVID-19

\section{Disease (COVID- I9) Burden}

In late December 2019, a cluster of pneumonia cases of unknown origin was reported in Wuhan, Hubei province of China. However the South Morning China Post dated November 17, 2019 reported a 55 years old individual from Hubei province was having similar symptoms. Wei Guixian, a shrimp seller of Hunan seafood market developed flu-like symptoms on 10th December 2019. As the illness persisted, Wei went to Wuhan Union Hospital for treatment. Wei strongly believed that she got infection from a toilet she shared with other meat sellers of Hunan market. A cluster of flu-like illness reported during the first week of December 2019 Hubei province, especially around Hunan market. Two third of the cases were attributed to Hunan market. But a person who had no exposure to Hunan market also got similar infection. This led the researchers to find out the origin of the virus. Initially, the researchers are of the view that snakes may be the reservoir of the new coronavirus. Detailed investigation including genome sequence analysis study revealed that bats could be a key reservoir. The receptor binding nature of the virus indicates the possibility of another beta-coronavirus, the host of which is not yet known. The biggest challenge in front of the scientists now is the identification of the intermediate zoonotic source that is responsible for the spread of the virus to humans.

Some of the recent studies showed that several viruses are present in sewage water. The study carried out in Paris in $5^{\text {th }}$ to $7^{\text {th }}$ March 2020 revealed the presence of coronavirus closely resembling COVID-19. Meanwhile, the scientists from Italy claimed that they have found traces of new CoV in sewage water collected from Milan and Turin in December 2019. These observations probably suggest the linkage of Guixian's belief that she got infection from the toilet of Hunan market. It is possible that the SARS-CoV-2 might have persisted in the waste water/sewage surrounding the Hunan market. No attempt has so far been made in Hubei province to study the presence of SARS-CoV-2 in waste water/ sewage water. How these coronavirus are reaching the sewage water and the possibility of human infection and further spread of these viruses are to be investigated in detail. It is possible that the new CoV might have reached the waste water through butchered wastes of wild animals, the meat of which the people used to take in some regions.

The information available so far is denying the possibility that the virus, SARS-CoV-2 is capable of spreading COVID-19, is emerged through laboratory manipulation. The binding nature of the virus in human system, the detection of coronavirus very similar to SARS-CoV-2 from animals such as bats refutes the remote possibility of laboratory manipulation theory of these viruses. The genetic data analysis clearly indicated that the SARS-CoV-2 is not derived from any previously used virus model. The scientists have postulated two possibilities with respect to the origin of the SARS-CoV. One possibility is that before zoonotic transfer there may be a natural selection in an animal. The other possibility is that natural selection in humans following zoonotic transfer. Detection of very close viral relatives of SARS-CoV-2 circulating in animals will be helpful in identifying the possible origin of this highly contagious virus. $^{23}$

The disease started in Wuhan, Hubei province in midNovember 2019 moved to other Chinese provinces by midJanuary 2020. Wuhan, being the transport hub in China, the disease quickly spread to throughout China. On 20th January 2020, Zhong Nanshan, a scientist from National Health Commission, China proclaimed the potential threat of the ongoing virus infection and it's capability for human to human transmission. From 25th February 2020 onwards, COVID-19 cases rapidly increased in Italy, Iran and South Korea. The first confirmed death was on 9th January 2020 in Wuhan. The first death outside China reported in Philippines. The first COVID-19 death outside Asia was in Paris. Considering the gravity of the disease outbreak, World Health Organization (WHO) on 30th January 2020 
declared the outbreak to be a Public health Emergency of International Concern. The Coronavirus situation report as on $29^{\text {th }}$ February 2020 showed that 79,394 confirmed COVID-19 cases and 2838 deaths (Case fatality rate $-3.57 \%$ ) were reported from China alone. A total of 6009 confirmed COVID-19 cases and 86 deaths (case fatality rate $-1.43 \%$ ) from 53 countries outside China were also reported as on $29^{\text {th }}$ February. ${ }^{24}$

\section{COVID- 19: Global Scenario in Brief}

Among the WHO Regions, the highest case fatality rate as per the report on $20^{\text {th }}$ June 2020 was in Europe (7.68\%) followed by Americas (5.16\%) and Western Pacific (3.58\%). ${ }^{25}$ Comparing other WHO regions the case fatality rate was low (2.23\%) in Eastern Mediterranean Region (Table 2).

Table 2.Global situation Report of Coronavirus disease (COVID- I9) as on 20 June, 2020

\begin{tabular}{|c|c|c|c|}
\hline WHO Regions & Cases & Deaths & $\begin{array}{c}\text { Case fatality } \\
\text { rate (\%) }\end{array}$ \\
\hline Africa & 208535 & 4750 & 2.28 \\
\hline Americas & 4163813 & 215903 & 5.16 \\
\hline $\begin{array}{c}\text { Eastern } \\
\text { Mediterranean }\end{array}$ & 878428 & 19560 & 2.23 \\
\hline Europe & 2509750 & 192645 & 7.68 \\
\hline $\begin{array}{c}\text { South-East } \\
\text { Asia }\end{array}$ & 560285 & 16814 & 3.00 \\
\hline $\begin{array}{c}\text { Western } \\
\text { Pacific }\end{array}$ & 203490 & 7288 & 3.58 \\
\hline
\end{tabular}

As per the WHO report dated $20^{\text {th }}$ June 2020 , the highest case fatality rate in the European Region was reported in France (19.17\%) followed by Belgium (16.03\%), Italy (14.52\%) and United Kingdom (14.06\%). ${ }^{25}$ In South-East Asia, India reported $3.28 \%$ of case fatality rate. Pakistan, in the Eastern Mediterranean Region, reported only $1.97 \%$ of case fatality rate (Table 3 and Figure 7).

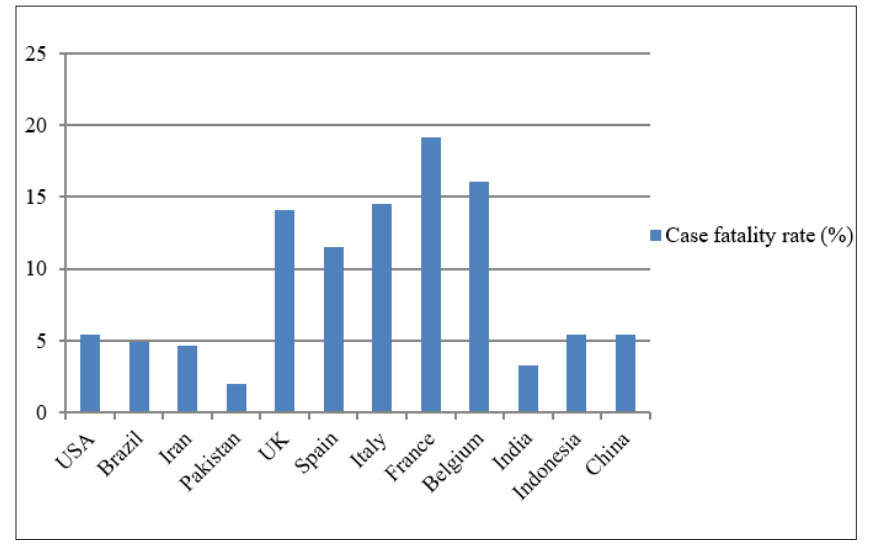

Figure 7.Case fatality rate (\%) in worst COVID- 19 affected countries as of 21.06 .2020

\section{COVID-1 9: National Scenario in Brief}

As per the situation report of COVID-19 dated 21st June 2020, Gujarat reported 26.62\% Case Fatality Rate (CFR) which is highest among all other Indian states. This is followed by Madhya Pradesh (21.70\%), Rajasthan (11.70\%), West Bengal (10.89\%), Maharashtra (10.26\%), Uttar Pradesh (8.89\%) and Delhi (8.86\%) (Table 4 and Figure 8). ${ }^{26}$ world (as of 20 June, 2020)

\begin{tabular}{|c|c|c|c|c|}
\hline \multirow{2}{*}{ Region/ Countries } & Cases & Deaths & Case fatality rate (\%) \\
\hline \multirow{3}{*}{ Americas } & $\begin{array}{c}\text { United States of } \\
\text { America }\end{array}$ & 2172212 & 118205 & 5.44 \\
\cline { 2 - 5 } & Brazil & 978142 & 47748 & 4.88 \\
\hline \multirow{3}{*}{ Eastern Mediterranean } & Iran & 200262 & 9392 & 4.69 \\
\cline { 2 - 5 } & Pakistan & 171666 & 3382 & 1.97 \\
\hline \multirow{3}{*}{ Europe } & $\begin{array}{c}\text { The United } \\
\text { Kingdom }\end{array}$ & 301819 & 42461 & 14.06 \\
\cline { 2 - 5 } & Spain & 245575 & 28315 & 11.53 \\
\cline { 2 - 5 } & Italy & 238011 & 34561 & 14.52 \\
\cline { 2 - 5 } & France & 154141 & 29551 & 19.17 \\
\cline { 2 - 5 } & Belgium & 60476 & 9695 & 16.03 \\
\hline \multirow{2}{*}{ South-East } & India & 395048 & 12948 & 3.28 \\
\hline & Indonesia & 43803 & 2373 & 5.42 \\
\hline Western Pacific & China & 84970 & 4645 & 5.47 \\
\hline
\end{tabular}


Table 4.Situation Report of COVID- 19 in worst affected states in India as of 2 I June, 2020

\begin{tabular}{|c|c|c|c|}
\hline States & Cases & Deaths & Case Fatality Rate (CFR) (\%) \\
\hline Maharashtra & 60161 & 6170 & 26.62 \\
\hline Gujarat & 6248 & 1663 & 2.93 \\
\hline Tamil Nadu & 25866 & 757 & 8.86 \\
\hline Delhi & 24558 & 2175 & 10.89 \\
\hline West Bengal & 5093 & 555 & 21.70 \\
\hline Madhya Pradesh & 2373 & 515 & 8.89 \\
\hline Uttar Pradesh & 6186 & 550 & 11.70 \\
\hline
\end{tabular}

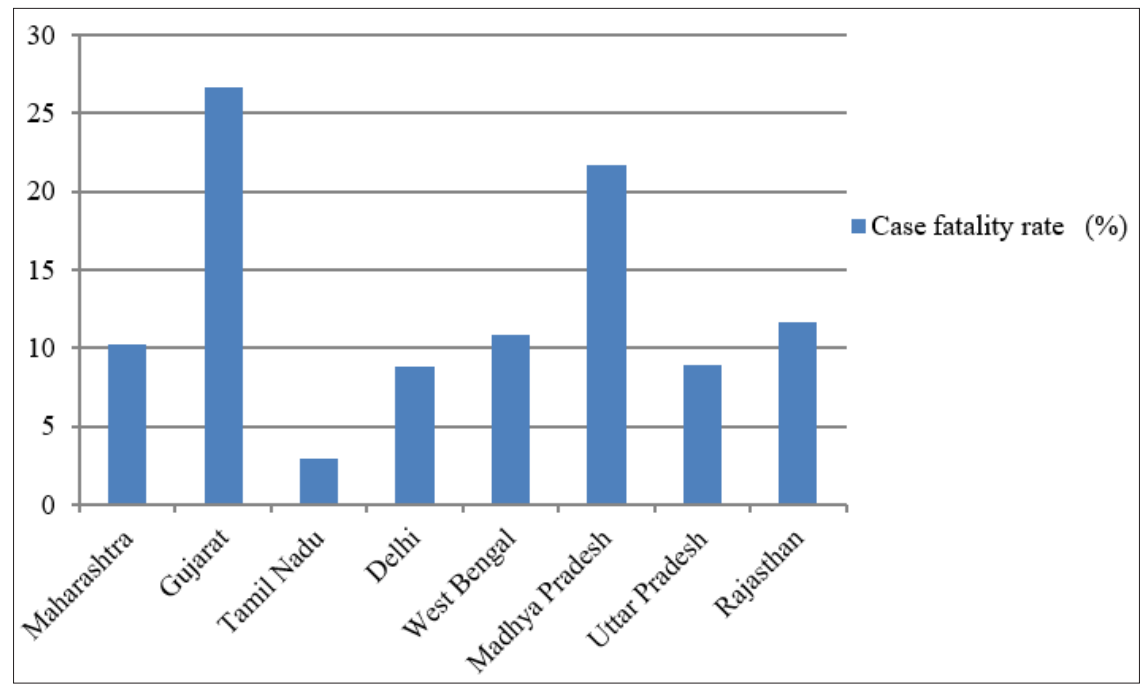

Figure 8.Case fatality rate (\%) in worst affected states of India as of 21.06 .2020

Table 5.District-wise details of COVID- I 9 cases, recovery rate and case fatality rate (as of 2I.06.2020)

\begin{tabular}{|c|c|c|c|c|c|}
\hline District (s) & COVID-19 cases & Number recovered & Recovery rate (\%) & Death (s) & Case fatality rate (\%) \\
\hline Thiruvananthapuram & 173 & 114 & 65.90 & 04 & 2.31 \\
\hline Kollam & 247 & 86 & 34.82 & 01 & 0.40 \\
\hline Alappuzha & 190 & 105 & 55.26 & 01 & 0.53 \\
\hline Kottayam & 162 & 68 & 41.98 & 0 & 0 \\
\hline Pathanamthitta & 197 & 64 & 32.49 & 01 & 0.51 \\
\hline Ernakulum & 175 & 65 & 37.14 & 01 & 0.57 \\
\hline Thrissur & 288 & 164 & 56.94 & 03 & 1.04 \\
\hline Idukki & 87 & 36 & 41.38 & 0 & 0 \\
\hline Malappuram & 360 & 160 & 44.44 & 03 & 0.83 \\
\hline Palakkad & 381 & 215 & 56.43 & 01 & 0.26 \\
\hline Kozhikode & 211 & 110 & 52.13 & 0 & 0 \\
\hline Wayanad & 74 & 43 & 58.10 & 01 & 1.35 \\
\hline Kannur & 355 & 247 & 69.57 & 04 & 1.12 \\
\hline Kasaragod & 410 & 291 & 70.98 & 0 & 0 \\
\hline Total & 3,310 & 1,747 & 52.77 & 21 & 0.63 \\
\hline
\end{tabular}




\section{COVID- 19: Kerala State Scenario}

The first case of COVID-19 pandemic in Kerala was reported on 30 January 2020, it was the first reported case in India. On 6th April 2020, the number of active cases in Kerala rose to 266. Since then COVID-19 cases reported daily in the state. However, there was no reported case on 1 May 2020. From June $7^{\text {th }}$ onwards, Keralites from other countries and states started returning to Kerala. Consequently the number of cases started increasing day by day, with the highest single-day hike (127 cases) on 20th June 2020. A total of 3,310 confirmed COVID-19 cases and 21 deaths were reported in Kerala as of 22nd June 2020. Thus, the overall case fatality rate remains $0.63 \%$ (ranged from 0 in Kottayam, Idukki, Kozhikode and Kasaragod to 2.31 in Thiruvananthapuram) which is lowest among all Indian states. The number of people recovered as of $22 \mathrm{nd}$ June is 1747. The overall recovery rate in Kerala is $52.77 \%$ (ranged from $32.49 \%$ of Pathanamthitta to $70.98 \%$ of Kasaragod) indicating the efficient patient care management of the state (Table 5 and Figure 9 \&10).

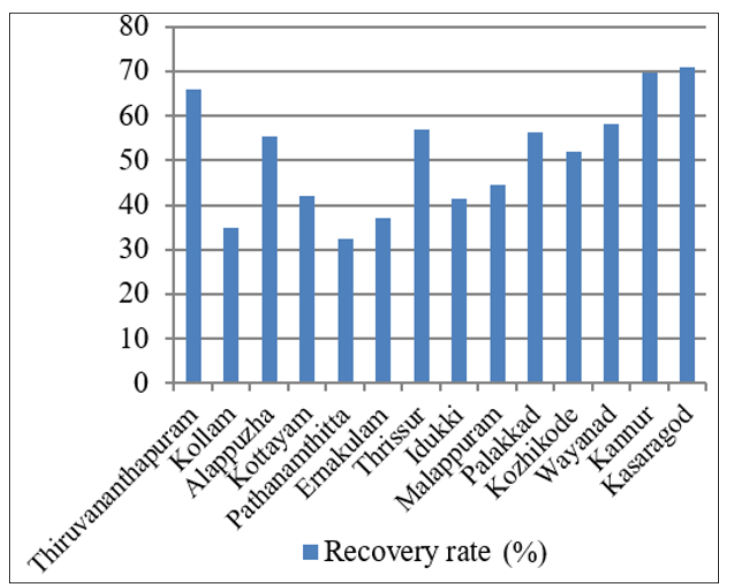

Figure 9.District-wise COVID- I 9 Recovery rate (\%) in Kerala as of 21.06 .2020

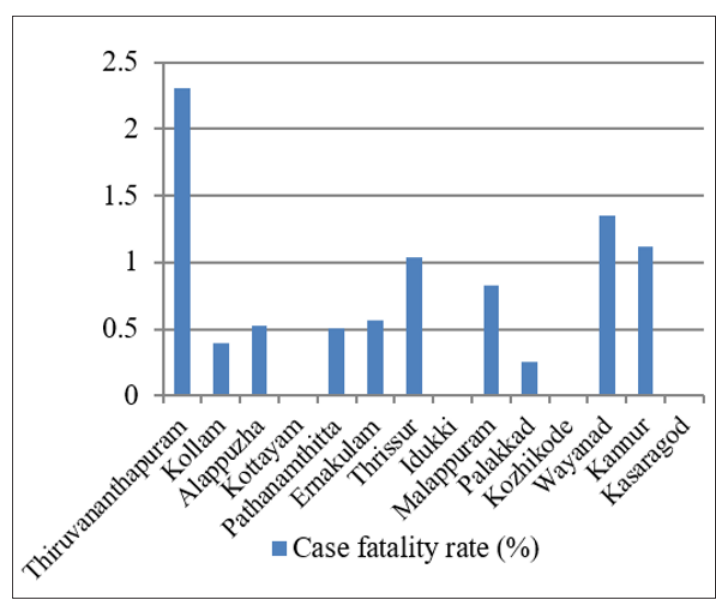

Figure 10.District-wise COVID- 9 Case fatality rate (\%) in Kerala as of 21.06 .2020

\section{Preparedness for COVID- 19 Control in Kerala}

The lessons and experiences that have resulted from the outbreak of Nipah in 2018 and 2019 provided adequate expertise to handle newly emerging infectious agents. ${ }^{27}$ Immediately after the first COVID-19 case reported in Kerala (also in India), surveillance activity is being intensified at Points of Entry (PoE) such as International Airports and Seaports, in health facilities and in the community including contact tracing and follow up around the confirmed case. Based on the available reports from different disease affected countries, indicated an average incubation period of 5 to 6 days, however it can be up to 14 days for nCoV. The infection was known to spread through droplet dischargedirect or indirect contact. Due to the unknown nature of the virus, double the quarantine period has been decided as quarantine period. Kerala is the only state in India that mandates 28 days for home quarantine, especially for foreign returned Keralites. This has been done earlier to protect the community from further infection. Recently, as per National guidelines, Government of Kerala has decided to keep the home quarantine period as 14 days for those who are coming from abroad or from other states.

The most essential activities such as surveillance, isolation/ quarantine, contact tracing, laboratory testing, awareness campaign, preventive measures, etc. are progressing well in the state. The medical and paramedical professionals were given proper training with regard to the preventive measures and precautions to be taken on the wake of COVID-19 threat in the state. The state government has introduced a mass hand washing campaign, "Break the Chain" program with an intention to educate the people about the importance of keeping hygiene for the control of contagious diseases like COVID-19.

Effective surveillance, Route map preparation of each infected person, precise contact tracing by a team of health and revenue officials, home/ hospital quarantine as per the decision of medical experts, timely laboratory diagnosis, case management in hospitals, awareness campaign of health department in association with Local Self-Governments (LSGs), Non-Government Organizations (NGOs), other social organizations, etc. rigorous service of police and fire force in keeping law and order and their vigil in hot spot areas/ containment wards, etc. pave for low case fatality rate and high recovery rate. The disease is not only under control in the state but also number one in terms of low Case Fatality Rate (CFR) and high recovery rate among all other Indian states. The state, therefore has won global acclaim in tackling this disaster by stringent measures undertaken by various departments/organizations and utilizing mostly domestic resources.

\section{Prevention}

Hygiene in all respects is the only way to get rid of this 
contagious disease. Effective surveillance, timely diagnosis and prompt treatment are the most essential components for the control of any communicable disease; COVID-19 is not an exception to this strategy.

The following activities were undertaken for the prevention and control of COVID-19, the disease caused by SARS-CoV- 2 .

- $\quad$ Surveillance: Screening and diagnosis of passengers at Points of Entry (PoE) such as International airports/ seaports.

- Quarantine: Quarantine and isolation are important components to check disease transmission in the community. As per the guidelines, those people above 60 or with co-morbidities should be shifted to the quarantine facility assigned to them. The confirmed cases and contact cases should be kept in separate isolation rooms in the hospital.

- Contact tracing: Under the guidance of Public health experts, the medical team should be entrusted for proper contact tracing, sample collection, if required and also to manage proper quarantine procedure.

- Social distancing measures: In order to curtail the rapid spread of COVID-19 among the community (community transmission), social distancing is the key intervention strategy.

Community awareness program should be organized to ensure the adherence of the community to follow the universal precautions.

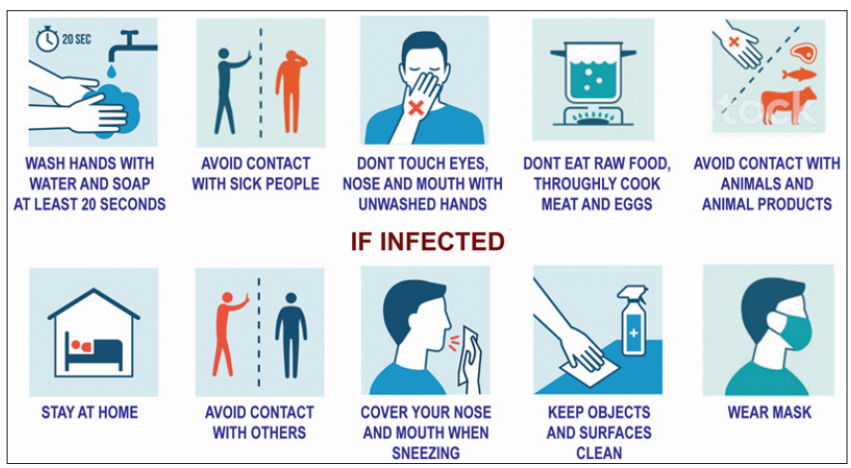

Figure I I.Preventive measures

- Wash the hands with soap and water at least for 20 seconds.

- Avoid close contact with infected people.

- Do not touch the eyes, nose and mouth with unwashed hands.

- Cover your cough or sneeze with tissue and dispose it properly.

- Keep objects and surfaces always clean.

\section{Conclusion}

The world has witnessed the emergence of many different coronaviruses that cause wide variety of human and animal diseases. The viruses have the ability to recombine, mutate, and infect many species and cell types. Hence these viruses will continue to emerge and evolve to cause disease outbreaks in both humans and animals.

The ability of these coronaviruses in selecting the reservoirs is unpredictable. Bats seem to be one of the potential reservoirs of most of the coronaviruses. How these viruses remain in bats without making any apparent clinical evidences in them is still a matter of great interest to the researchers. Owing to the lack of effective medicine/vaccine, the best option to control human coronaviruses remains in three factors- DHS: Distancing (D), Hand washing (H) and Sanitization practices (S). Rapid diagnostic testing, contact tracing, quarantine and isolation, disease management as per treatment protocol and community awareness through IEC/BCC campaign are also important components for the control of this highly contagious and dangerous disease.

\section{Acknowledgement}

We thank the District Surveillance Officers of all the fourteen districts of Kerala for their help in COVID-19 outbreak investigation. Also thank Sh. A.W. Joseph, Graphic designer, Kavya Printers, Cherthala for the help in diagrammatic illustration.

\section{Conflict of Interest: None}

\section{References}

1. Fehr AR, Perlman S. Coronaviruses: an overview of their replication and pathogenesis. Methods $\mathrm{Mol}$ Biol 2015; 1282: 1-23.

2. de Groot RJ, Baker SC, Baric R et al. Family Coronaviridae. In: King AMQ, Lefkowitz E, Adams MJ (eds.). Ninth Report of the International Committee on Taxonomy of Viruses. Elsevier, Oxford. pp. 806-828.

3. Corman VM, Muth D, Niemeyer D et al. Hosts and sources of endemic human coronaviruses. Advances in Virus Research 2018; 100: 163-188.

4. Jia HP, Look DC, Shi L et al. ACE2 receptor expression and severe acute respiratory syndrome coronavirus infection depend on differentiation of human airway epithelia. J Virol 2005; 79: 14614-21.

5. Beaudette F, Hudson C. Cultivation of the virus of infectious bronchitis. J Am Vet Med Assoc 1937; 90: 51-8.

6. Ananthanarayan R, Jayaram Paniker CK. Textbook of Microbiology, Fifth Edition, Orient Longman Ltd., 1998.

7. Saif LJ. Animal coronaviruses: what can they teach us about the severe acute respiratory syndrome? Rev Sci Tech 2004; 23: 643-660.

8. Lai MM. RNA recombination in animal and plant viruses. Microbiol Rev 1992; 56: 61-79.

9. Plowright RK, Eby P, Hudson PJ et al. Ecological dimensions of dynamics of emerging bat virus spillover. Proc Biol Sci 2015; 282: 20142124. 
10. Yadav PD, Shete AM, Kumar GA et al. Nipah virus

1867-78. sequences from humans and bats during Nipah outbreak, Kerala, India, 2018. Emerg Infect Dis 2019; 25: 1003-6.

11. Yadav PD, Shete A, Dimpal A et al. Detection of coronaviruses in Pteropus \& Rousettus species of bats from different states of India. Indian J Med Res. 2020.

12. Hamre D, Procknow JJ. A new virus isolated from the human respiratory tract. Proc Soc Exp Biol Med 1966; 121: 190-3.

13. McIntosh K, Dees JH, Becker WB et al. Recovery in tracheal organ cultures of novel viruses from patients with respiratory diseases. Proc Natl Acad Sci U.S.A. 1967; 57: 933-940.

14. Richard SD. Responding to global infectious disease outbreaks: Lessons from SARS on the role of risk perception, communication and management. Social Science and Medicine 2006; 63(12): 3113-23.

15. Lau SKP, Woo PCY, Li KSM et al. Severe acute respiratory syndrome coronavirus-like virus in Chinese horseshoe bats. Proc Natl Acad Sci 2005; 102(39): 14040-5.

16. Li W, ZhengI S; Meng Y et al. Bats are Natural reservoirs of SARS-like Coronaviruses. Science 2005; 310(5748): 676-9.

17. Zaki AM, van Boheemen S, Bestebroer TM et al. Isolation of a novel coronavirus from a man with pneumonia in Saudi Arabia. N Engl J Med 2012; 367: 1814-20.

18. The Economic Times. A Wuhan shrimp seller identified as coronavirus 'patient zero'. 2020.

19. Lu H, Tang CW, Tang Y. Outbreak of pneumonia of unknown etiology in Wuhan China: the mystery and the miracle. J Medl Virol 2020.

20. Shi Z, Hu Z. A review of studies on animal reservoirs of SARS coronavirus. Virus Res 2008: 133(1): 74-87.

21. Wang $N$, Shi $X$, Jiang $L$ et al. Structure of MERS-CoV spike receptor-binding domain complexed with human receptor DPP4. Cell Res 2013; 23(8): 986.

22. Li B, Si HR, Zhu Y et al. Discovery of Bat Coronaviruses through surveillance and Probe Capture- Based Next Generation Sequencing. Insphere 2020: 5(1).

23. Shereen MA, Khan S, Kazmi A et al. COVID-19 infection: Origin, transmission and characteristics of human coronaviruses. Journal of Advanced Research 2020; 24: 91-8.

24. WHO. Coronavirus Disease 2019 (COVID-19) Situation Report-49. 2020.

25. WHO. Coronavirus disease (COVID-19) Situation Report-152. 2020

26. MH \& FW. COVID-19 State-wise Status, Ministry of Health and Family Welfare, Government of India, 2020

27. Arunkumar G, Chandini R, Mourya DT et al. Nipah Investigators and Health Study Group. Outbreak Investigation of Nipah virus Disease in Kerala, India, 2018. The Journal of Infectious Diseases 2019; 219(12): 